\title{
Adoption of Purple Tea Farming as A Coping Mechanism to Climate Change, Kericho County, Kenya (2014)
}

\author{
Kimtai Ronald Kachuwai ${ }^{1}$, Dr. Benson Karanja ${ }^{2}$, Dr. Rebecca Karanja ${ }^{3}$ \\ ${ }^{1}$ MSC. Environmental Legislation and Management, Institute of Energy and Environmental Technology, Jomo Kenyatta University of \\ Agriculture and Technology (JKUAT), P.O. Box 62000- 00200 NAIROBI, KENYA. \\ ${ }^{2}$ Institute of Energy and Environmental Technology, Jomo Kenyatta University of Agriculture and Technology, P.O. Box 62000- 00200 \\ NAIROBI, KENYA \\ ${ }^{3}$ Department of Botany, Jomo Kenyatta University of Agriculture and Technology, P.O. Box 62000- 00200 NAIROBI, KENYA
}

\begin{abstract}
Sub-Saharan Africa is home to almost 900 million people, $60 \%$ of whom are dependent on agriculture for their livelihood, FAO (2006). Africa's farmers are among the most vulnerable to climate change, despite having the world's lowest rate of greenhouse gas emissions per person, Charles et.al (2010). Higher temperatures, variations in rainfall patterns and more frequently occurring extreme climate events are threatening food security. With the current climatic conditions, purple tea is considered favorable in terms of productivity, health, market and resistance to changing weather patterns, Kamunya, (2015). Although, there are widespread adaptation measures under different sectors, they are not fully being realized due to socio-economic and other constraints, GoK (2010). The study adopted both quantitative and qualitative study design to generate meaningful conclusion, Creswell, J. W., \& Plano Clark, V. L. (2007). Various sampling techniques used involved; purposive, systematic, cluster stratified and random sampling to ensure representation of the whole area. Data was collected by use of CO2 and RGR algorithm, questionnaires, in-depth interviews, literature review, observation and photography. And, Data was analyzed by use of both descriptive and inferential statistics to answer the research questions. The findings of the study are expected to work as a turning point for tea farmers to realize and acknowledge the benefits of purple tea farming as far as economic, environmental, health and other spheres are concerned. It is expected that the findings of this study will enable scientific researchers and policy makers make wise decisions regarding the adoption of available adaptation measures to achieve the sustainable development in Kenya.
\end{abstract}

Keywords: Adoption; Purple, Coping, Mechanism

List of Abbreviations

C - Carbon

CO2 - Carbon Dioxide

RGR - Relative Growth Rate

IPCC - Intergovernmental Panel on Climate Change

KTDA - Kenya Tea Development Authority

TRFK - Tea Research Foundation of Kenya

GHG - Green House Gases

TAR - Third Assessment Report

TPP - Total Polyphenol

TC - Total Catechin

TBK - Tea Board of Kenya

\section{Introduction}

Climate change is one of the all-encompassing global environmental changes likely to have deleterious effects on natural and human systems, economies and infrastructure Otto S, (1999). The risks associated with it call for a broad spectrum of policy responses and strategies at the local, regional, national and global level. While mitigation seeks to limit climate change by reducing the emissions of GHG (greenhouse gases) and by enhancing 'sink' opportunities, adaptation aims to alleviate the adverse impacts through a wide-range of system-specific actions (Fussel and Klein, 2002).

Kenyan tea has for many years been sold in its whole form, although in recent times the tea sector has been looking at the likelihood of selling tea extracts (Tea Board of Kenya, 2011). Tea is primarily processed using the Cut, Tear and Curl (CTC) technique to guarantee maximum cuppage per unit weight

Albeit both mitigation and adaptation measures must be pursued to tackle the climate change problem and to create an effective and inclusive international climate change regime, more attention has been devoted to mitigation in the past, both in scientific research and policy debate. Sensitivity to the issue of adaptation has grown over the last couple of years, particularly after the IPCC (Intergovernmental Panel on Climate Change) TAR (Third Assessment Report, 2001). Adaptation has now emerged as an urgent policy priority, prompting action both within and outside the climate change negotiations (Parry et al. 2005).

\section{Methodology}

The establishment rate for purple tea farming was determined under separate acreage cadres that was identified as; $2,4,6,8,10$, and $>10$. The replacement possibilities were also determined under the same acreage cadres. The productivity ratios were analyzed during both wet and dry season for the two varieties of green and purple tea. The RGR was also determined under various stages of the tea which was stipulated in number of years. The $\mathrm{CO} 2$ sequestration potentials were determined under varied circumstances that included; Above ground and Below 


\section{International Journal of Science and Research (IJSR) \\ ISSN (Online): 2319-7064 \\ Index Copernicus Value (2013): 6.14 | Impact Factor (2015): 6.391}

ground $\mathrm{CO} 2$ sequestration, Acreage $\mathrm{CO} 2$ sequestration and seasonal sequestration using; For trees with $\mathrm{D}<11$ : $\mathrm{W}=$ $0.25 \mathrm{D} 2 \mathrm{H}$, whereby the following formula was used:

C Seq. $=\{\underline{\mathrm{W}=0.25(\mathrm{D}) 2 \mathrm{H}\}}$

$$
\mathrm{C} \text { ratio. }
$$

Growth rate algorithm was used to determine the Relative Growth Rate of purple tea as compared to RGR of green tea. RGR $=\underline{\mathrm{L}}_{2}-\underline{\mathrm{L}}_{1}$, Where $\mathrm{L} i$ is the length of the plant at time(day) $t i$

$$
t_{2}-t_{1}
$$

The Equipments that were used included HPLC related equipments (sampler, detector meter etc), portable ruler, questionnaires, and portable cameras. The parameters that were measured and analyzed included; RGR, CO2 Sequestration potentials, sensory and chemical composition. Among the chemical compositions that were analyzed were; Catechins, Total plyphenols, Garlic acid, Caffein and Theanine.

\section{Results}

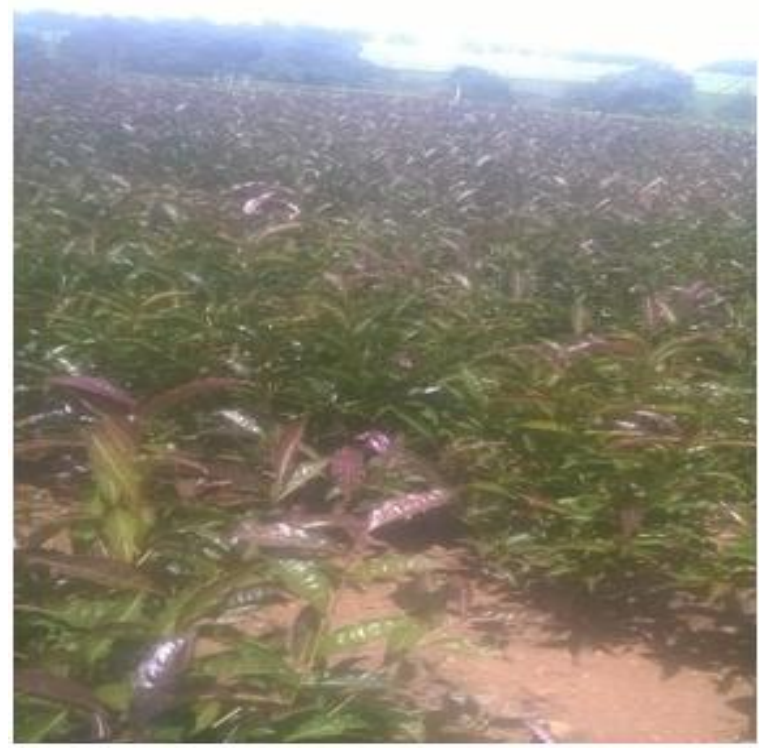

Plate 1: Established field of Purple Tea

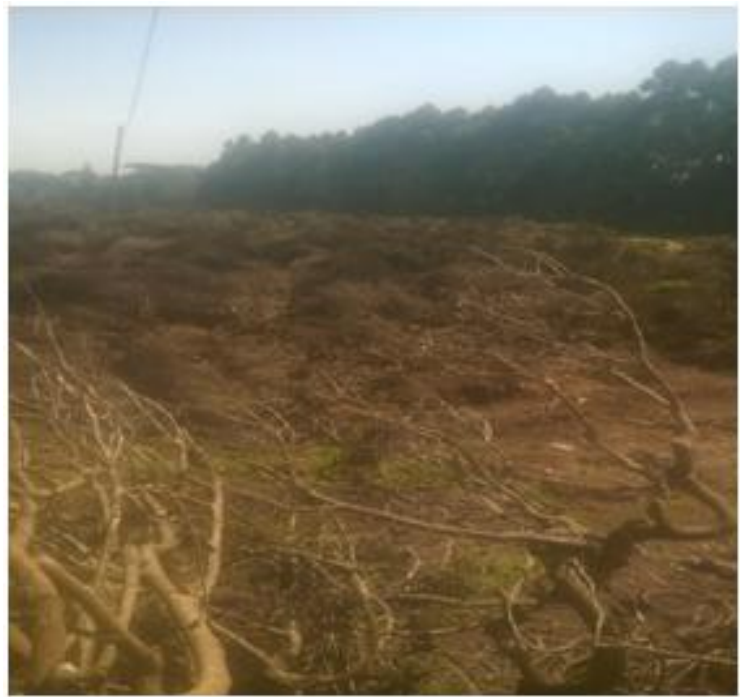

Plate 2: Uprooting of Green Variety for replacement by the Purple Variety

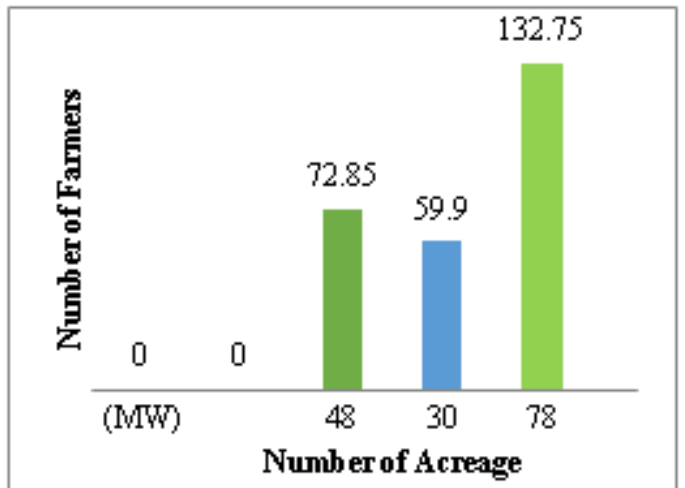

Figure 1: Number of Farmers per Acreage

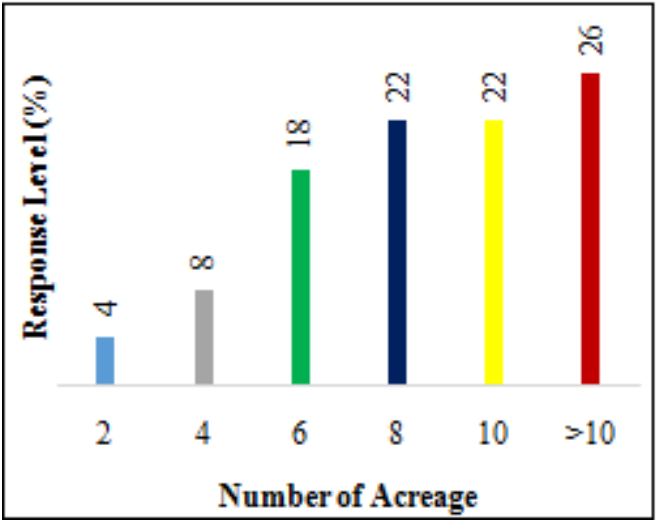

Figure 2: Availability of Extension Services according to Acreage

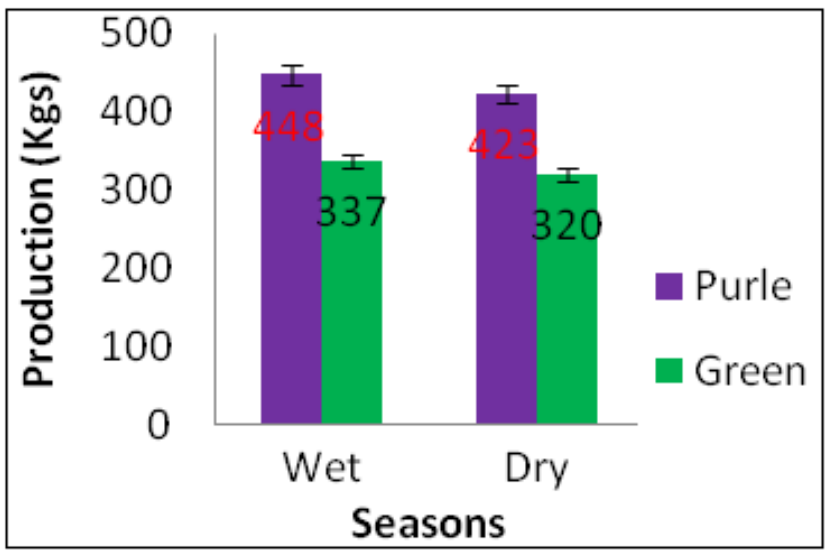

Figure 3: Pocessing factors across the two Varieties

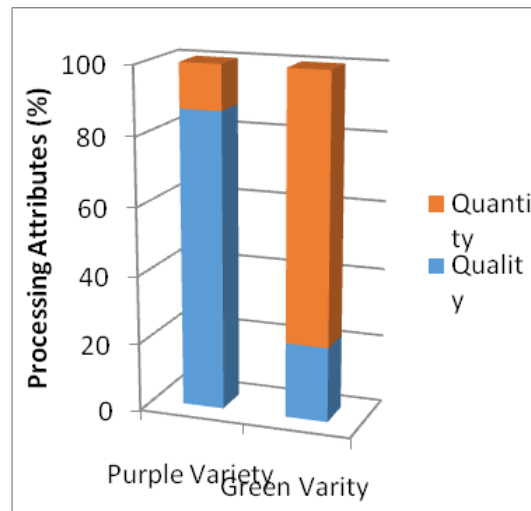

Figure 4: Production analysis across varieties during Wet and Dry seasons

Volume 5 Issue 6, June 2016 www.ijsr.net 


\section{International Journal of Science and Research (IJSR) \\ ISSN (Online): 2319-7064}

Index Copernicus Value (2013): 6.14 | Impact Factor (2015): 6.391

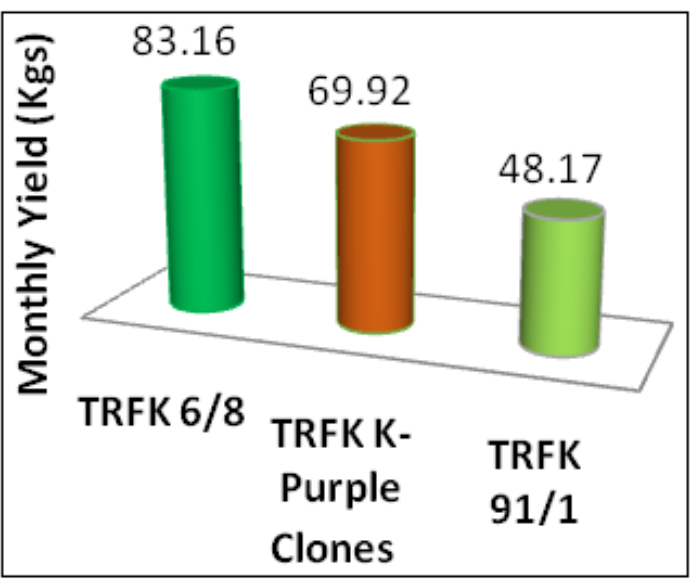

Figure 5: Production analysis for selected clones of Green and Purple Varieties

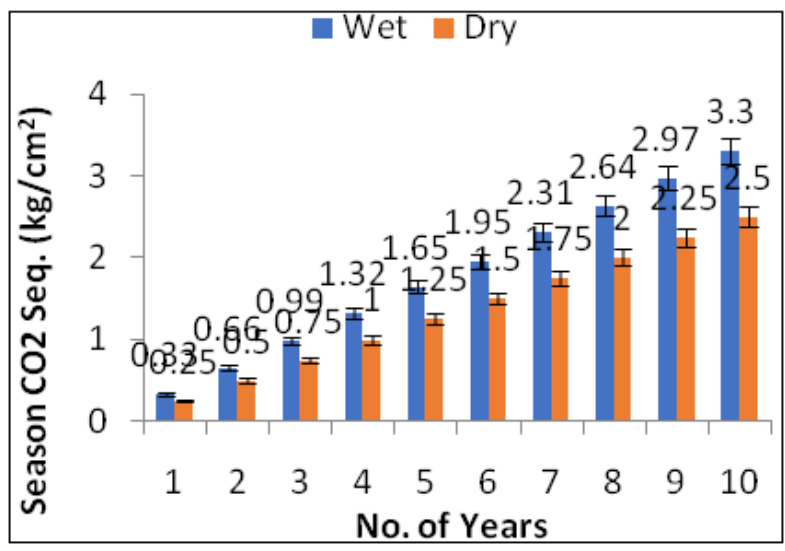

Figure 6: Precipitation Differentials of Purple Variety Growth Rate and Carbon Sequestration

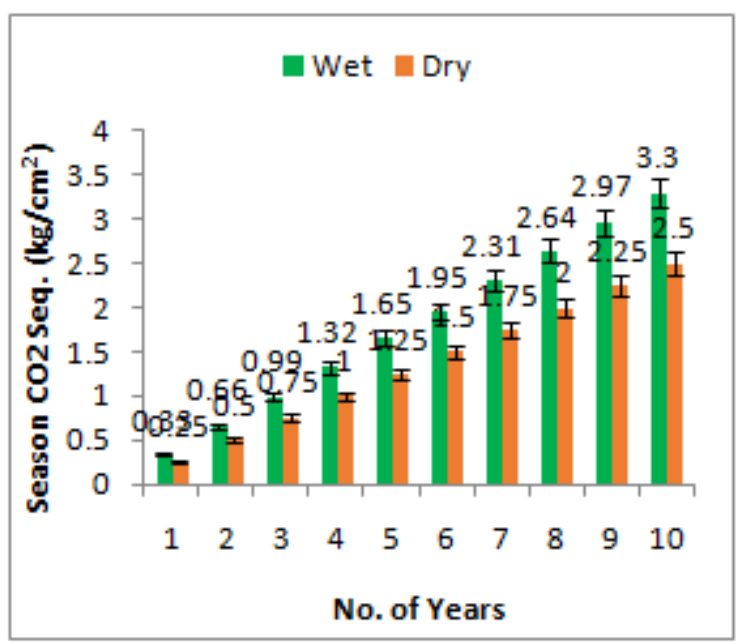

Figure 7: Precipitation Differentials of Green Variety Growth Rate and Carbon Sequestration
- TRFK 6/8 - TRFK 91/1 - TRFK K-Purple

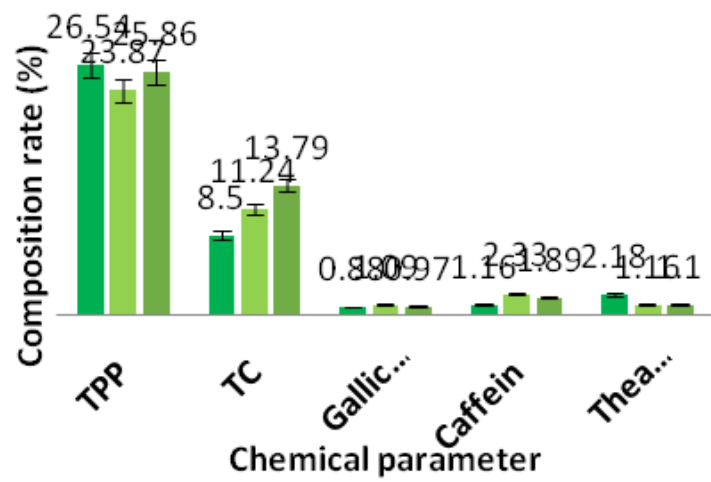

Figure 8: Sensory and Chemical Parameters Evaluation of Green and Purple Tea varieties

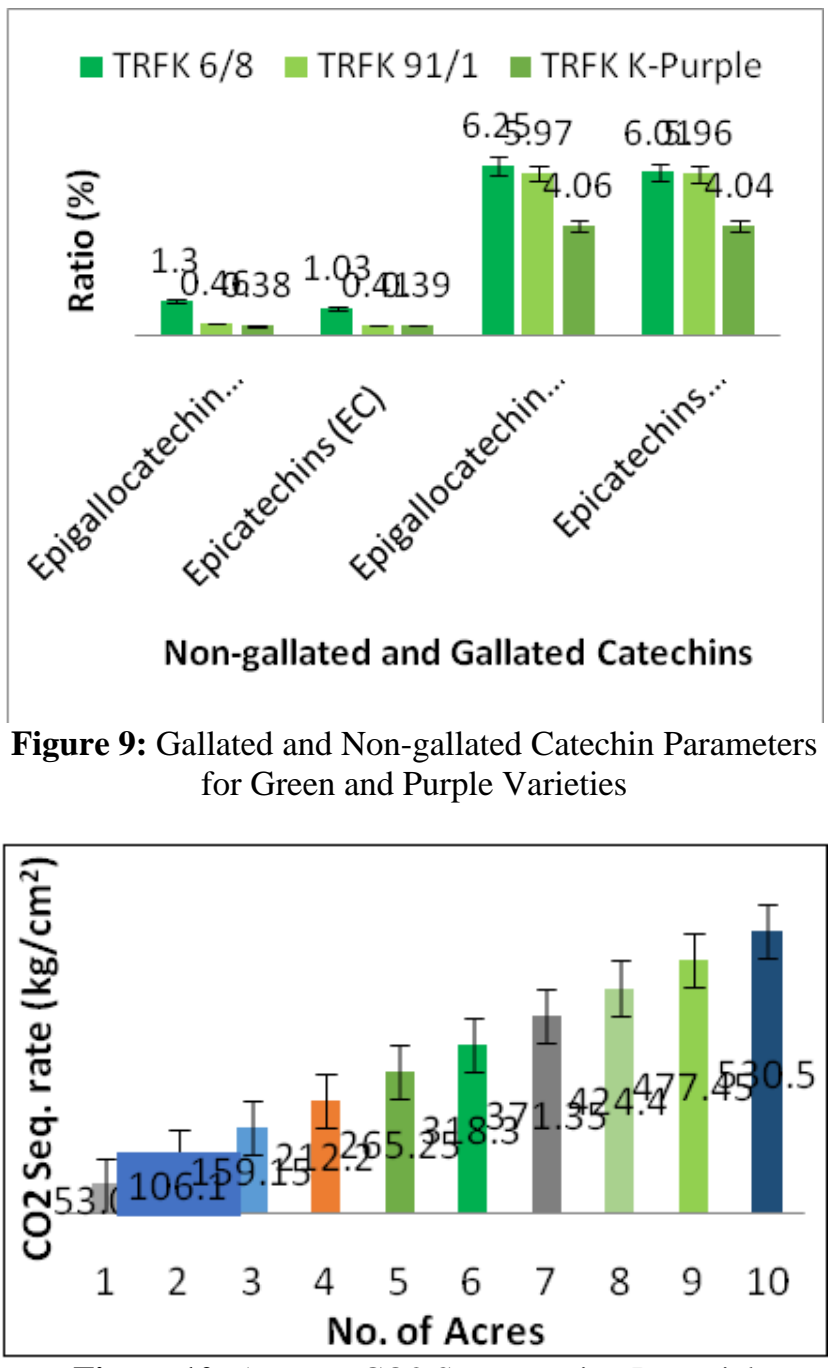

Figure 10: Acreage CO2 Sequestration Potential

Volume 5 Issue 6, June 2016 www.ijsr.net 
International Journal of Science and Research (IJSR)

ISSN (Online): 2319-7064

Index Copernicus Value (2013): 6.14 | Impact Factor (2015): 6.391

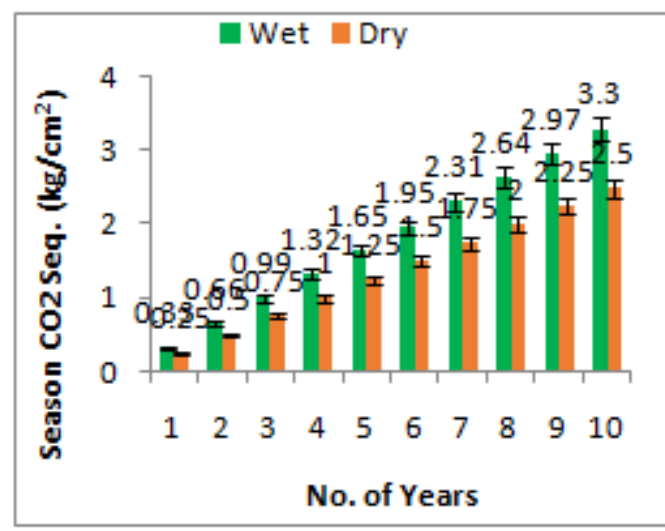

Figure 11: Relative Growth Rate for Green Tea Variety and $\mathrm{CO} 2$ Sequestration

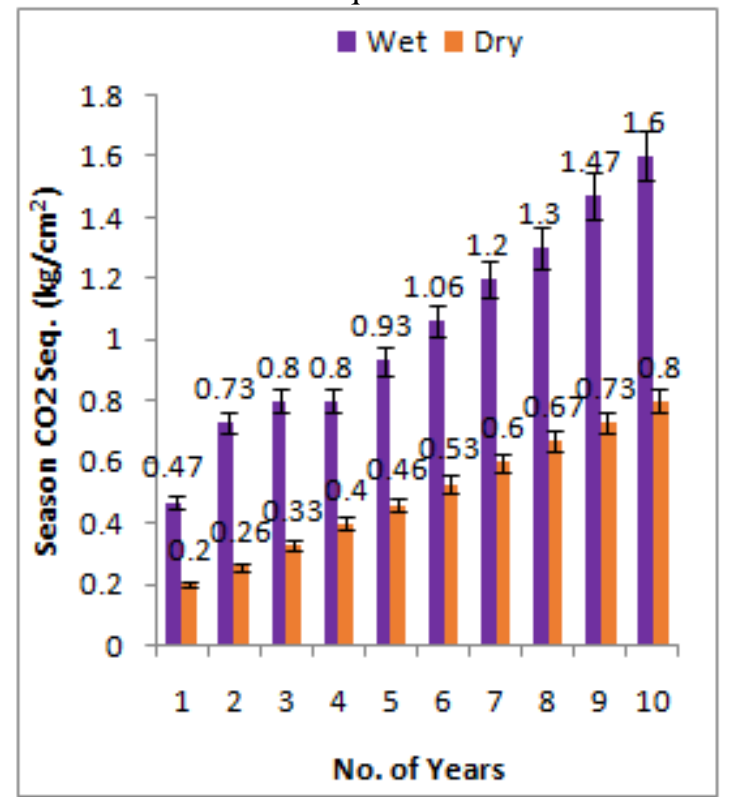

Figure 12: Relative Growth Rate for Purple Tea Variety and $\mathrm{CO} 2$ Sequestration

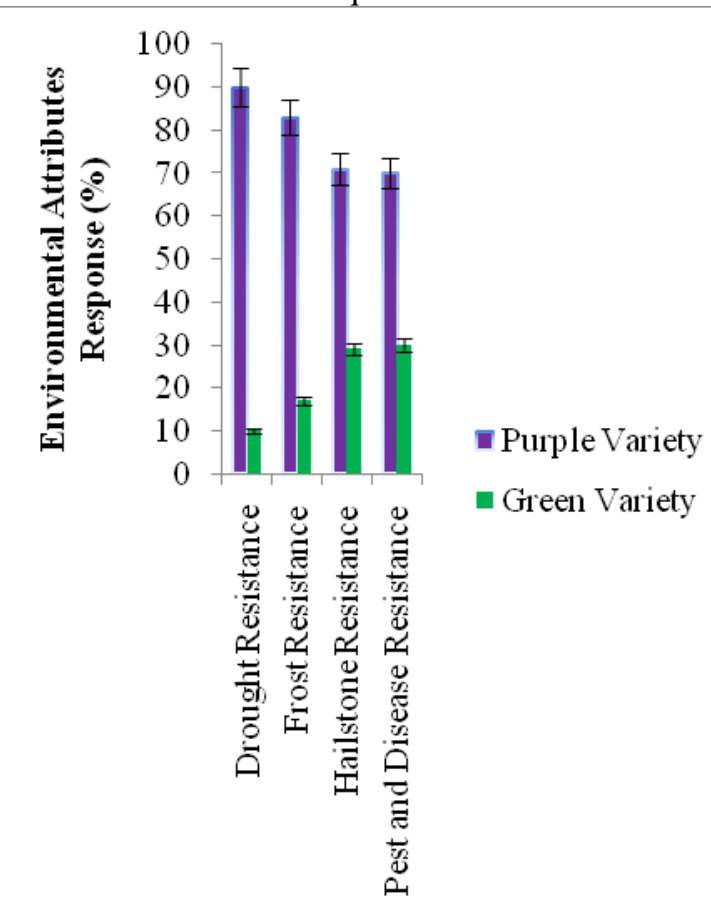

Figure 13: Variety Streangth Towards Environmental Parameters
Table 1: Above ground CO2 Sequestration Potential

\begin{tabular}{|c|c|c|c|c|}
\hline $\begin{array}{c}\text { Age } \\
\text { Factor }\end{array}$ & $\begin{array}{c}\mathrm{D} \\
(\mathrm{cm})\end{array}$ & $\begin{array}{c}\mathrm{H} \\
(\mathrm{cm})\end{array}$ & $\begin{array}{c}\text { CO2 Sequestration } \\
\text { Potential }\left(\mathrm{kg} / \mathrm{cm}^{2}\right)\end{array}$ & $\begin{array}{c}\text { Cumulative Frequency } \\
\text { for CO2 Sequestration }\end{array}$ \\
\hline 1 & 0.5 & 38 & 4.36 & 18.49 \\
\hline 2 & 0.6 & 44 & 7.27 & 53.29 \\
\hline 3 & 0.8 & 48 & 14.1 & 198.81 \\
\hline 4 & 0.9 & 52 & 19.32 & 372.49 \\
\hline 5 & 1 & 58 & 26.61 & 707.56 \\
\hline 6 & 1.2 & 61 & 40.3 & 1624.09 \\
\hline 7 & 1.4 & 64 & 57.54 & 3306.25 \\
\hline 8 & 1.6 & 66 & 77.51 & 6006.25 \\
\hline 9 & 1.6 & 67 & 78.68 & 6193.69 \\
\hline 10 & 1.8 & 70 & 104.04 & 10081.6 \\
\hline & & & Mean=42.97 & S.D $=34.71$ \\
\hline
\end{tabular}

Table 2: Below Ground CO2 Sequestration Potential \begin{tabular}{|c|c|c|c|c|}
\hline Age & D & H & CO2 Sequestration Cumulative Frequency \\
\hline
\end{tabular} \begin{tabular}{|c|c|c|c|c|} 
Factor & $(\mathrm{cm})$ & $(\mathrm{cm})$ & Potential $\left(\mathrm{kg} / \mathrm{cm}^{2}\right)$ & for $\mathrm{CO} 2$ Sequestration \\
\hline
\end{tabular}

\begin{tabular}{|c|c|c|c|c|}
\hline 1 & 0.5 & 1.2 & 1.7 & 2.89 \\
\hline 2 & 0.6 & 1.5 & 3.5 & 12.25 \\
\hline 3 & 0.8 & 1.8 & 7.4 & 54.76 \\
\hline 4 & 0.9 & 1.8 & 8.3 & 68.89 \\
\hline 5 & 1 & 2 & 12.2 & 148.84 \\
\hline 6 & 1.2 & 2.2 & 18.8 & 353.44 \\
\hline 7 & 1.4 & 2.5 & 30.8 & 948.64 \\
\hline 8 & 1.6 & 2.7 & 43.4 & 1883.56 \\
\hline 9 & 1.6 & 2.8 & 47.9 & 2294.41 \\
\hline 10 & 1.8 & 2.9 & 59.3 & 3516.49 \\
\hline & & & Mean=23.33 & S.D $=20.66$ \\
\hline
\end{tabular}

\section{Discussion}

The acreage indications was determined as a result in determining the possibility of farmers shifting from the old variety to new variety of purple tea. This indicated that availability of land was a major setback by farmers adopting the new variety with most famers owning less than 6 acres of land that indicates $82.6 \%$ while few famers had acres above 6 that indicates $17.4 \%$.

The availability of extension services was determined by the number of acreage owned by the smallholder farmers. The results depict that, extension officers were concentrating to farmers that own large tracts of land. It's evident that, farmers with more than 10 acres got a huge share of the extension services at $26 \%$ followed by $22 \%$ for both farmers owning 8 and 10 acres respectively. Farmers with 6 acres are slightly considered at $18 \%$ since they are close to those with above 8 acres in terms of economic and social perspectives.

Being a new variety, the purple tea showed a high percentage in terms of the quality than quantity as compared by the green variety. The ratios were (13\%) and $(87 \%)$ respectively as far as quantity and quality is concerned for purple variety. The green variety showed a high rate of quantity than quality. (78\%) and (22\%) quantity and quality respectively for green variety. The difference between two results was due to the great medicinal, marketing and production attributes attached to the purple variety which makes it to generate high quality attributes.

The production mean of purple tea was higher during both wet and dry seasons since their shooting rates of the

Volume 5 Issue 6, June 2016 www.ijsr.net

Licensed Under Creative Commons Attribution CC BY 


\section{International Journal of Science and Research (IJSR) \\ ISSN (Online): 2319-7064}

Index Copernicus Value (2013): 6.14 | Impact Factor (2015): 6.391

pluckable buds are higher than the green tea. There was no significant difference $(\mathrm{P}=0.05)$ for production of the two varieties between the two seasons. The $t_{c a l}=0.14<t_{t a b}=2.92$, $\mathrm{P}_{c a l}=0.9015>\mathrm{P}_{t a b}=0.05$. The purple variety mean values were high during both wet and dry seasons at $448 \mathrm{kgs}$ and $423 \mathrm{kgs}$ respectively. While the green variety had the least mean value at $337 \mathrm{kgs}$ and $320 \mathrm{kgs}$ respectively.

The $t_{\text {calculated }}$ for the selected clones was 17.61 which was greater than the $t$ tabulated at $95 \%$ confidence level. The results showed that there was a significance difference $(\mathrm{P}<0.05)$ between the monthly yields of the three clones. Whereby, TRFK 6/8 recorded the highest yield of (83.16 $\mathrm{Kgs})$ followed by TRFK K-Purple $(69.92 \mathrm{Kgs})$ and the least was TRFK 91/1 with (48.17 Kgs). The results shows that, clonal improvement is need to determine a complete and more productive clone as far as purple tea variety is concerned in order to boost productivity across the seasons.

The precipitation defirential for purple variety with wet season showed high mean figures across the 10 years evaluated plant specimens. It was depicted that, the results under wet season doubled the ones under dry season from the least to the highest number of years. Year 1, wet season showed $0.33 \mathrm{lbs}$ and dry season showed $0.25 \mathrm{lbs}$, Year 2, wet was $0.66 \mathrm{lbs}$ and dry $0.5 \mathrm{lbs}$, Year 3 and 4, wet 0.99 , $0.1 .32 \mathrm{lbs}$ and dry $0.75,1 \mathrm{lbs}$ respectively. It showed that, the relative growth rate for two plant specimens during wet season responded similarly and absolutely different during the dry season which the maturity rate in terms of years was the critical factor of difference.The $t$-test results for purple variety showed that there was no significant difference $(\mathrm{P}<0.05)$ between dry and wet season carbon sequestration potentiality. $\mathrm{t}_{\mathrm{c} a l}=0.131<t_{t a b}=1.812, P_{c a l}=0.8984>\mathrm{P}_{t a b}=0.05$

The difference between the dry and wet seasons of the green variety is absolutely different from the ones for purple tea across the seasons. Year 1 results showed $0.33 \mathrm{lbs}$ wet and $0.25 \mathrm{lbs}$ dry; Year 2, wet 0.66 and dry 0.5; Year 3, wet 0.99 lbs and dry 0.75 and the highest one, Year 10, wet was 3.3 lbs and dry $2.5 \mathrm{lbs}$. The t-test results for green variety showed no significant difference $(\mathrm{P}<0.05)$ between the dry and wet seasons as far as $\mathrm{CO} 2$. Sequestration is concern. The $t_{c a l}=0.1104<t_{\text {tab }}=1.812, \mathrm{P}_{c a l}=0.9143>\mathrm{P}_{t a b}=0.05$.

This showed that, wet season and dry of green variety had a relatively low significant difference $<0.5$ compared to the ones for purple variety that had absolute significant difference $=$ or $>0.5$ of $\mathrm{CO} 2$ sequestration between the respective seasons. The green variety is under no hybridization which stands a better chance of sequestering the $\mathrm{CO} 2$ more than the purple variety.

The results for TPP showed that there was no significance difference $(\mathrm{P}<0.05)$ between the three purple tea clones. Since, $t_{c a l}=30.4876>t_{t a b}=12.924, P_{c a l}=0.001<P_{t a b}=0.05$. It was known that, the TRFK 6/8 had the highest TTP due to both presence of green and purple chlorophyll combined. The TRFK K-Purple showed 25.86 as a result of sizeable purple chlorophyll as compared to green chlorophyll. TRFK 91/1 showed slightly low TPP since green chlorophyll was dominant.
The results for TC depicts that there was no significant difference $(\mathrm{P}<0.05)$ for the three selected and evaluated clones. $t_{c a l}=6.6627<t_{t a b}=12.924, P_{c a l}=0.0218<P_{t a b}=0.05$. KPurple showed the highest value ratio of $13.79 \%$ followed by TRFK $91 / 1$ at $11.24 \%$ and TRFK $6 / 88.5 \%$ as the lowest. The ratio was as a result of the dominance of both purple and green amongst the evaluated clones. Catechins can have protective effects to neurons. Also being the antioxidant, it helps in oxidation and reduces metabolism of dough.

Significant difference was not noted in all the three evaluated clones to determine the presence of gallic acid. Since, $t_{c a l}=0.3288<t_{\text {tab }}=12.924, P_{c a l}=0.7735>P_{t a b}=0.05$. The results showed that, only clone TRFK 91/1 had the highest value ratio above 1 while the rest their ratios were below 1 . The noted results were; TRFK 91/1 (1.09\%), TRFK KPurple $(0.97 \%)$ and TRFK 6/8 (0.88\%). The subsequent results showed that, gallic acid was common in the clones that have both green and purple chlorophyll in high ratios as compared to the clones that have relatively low distributed chlorophylls.

There was no significant difference $(\mathrm{P}<0.05)$ as per the results of the three evaluated clones in determining the presence of Caffein. Since, $t_{\text {cal }}=2.3252<t_{\text {tab }}=12.924$, $P_{c a l}=0.1456>P_{t a b}=0.05$. The result showed that, among the TRFK 91/1, TRFK K-Purple and TRFK 6/8 the ratio of caffeine was quite little that ranges between $1-3 \%$. The highest recorded value was TRFK 91/1 that indicated (2.33\%) followed closely by TRFK K-Purple at (1.89\%). While TRFK 6/8 recorded the lowest value at (1.16\%). Thus, the results indicate that there could be a reduced ratio of the caffeine components in various clones if research is undertaken through hybridization.

Theanine results showed that there was no significant difference $(\mathrm{P}<0.05)$ according to the evaluated clones to determine the Theanine ratio. Since, $t_{c a l}=1.3698<t_{\text {tab }}=12.924, \quad P_{\text {cal }}=0.3043>P_{\text {tab }}=0.05 . \quad$ The recorded results showed that clone TRFK $6 / 8$ had the highest levels of Theanine at $(2.18 \%)$, which was followed by clone TRFK $91 / 1$ at $(1.16 \%)$. Clone K-Purple recorded the lowest levels of Theanine at $(1.1 \%)$. This therefore indicated that, Theanine ratio is low on the purple chlorophyll as compared to green dominating chlorophyll clones.

The results for Gallated and Non-Gallated Catechin showed that TRFK 6/8 had the highest mean in all, EGC (1.3\%), EC $(1.03 \%)$, EGCG $(6.25 \%)$ and ECG $(6.01 \%)$ due to its dominating green chlorophyll. TRFK 91/1 was slightly lower than TRFK 6/8. The results of TRFK in both nongallated and gallated catechins were; EGC $(0.46 \%)$, EC $(0.41 \%)$, EGCG $(5.97 \%)$ and ECG (5.96\%). TRFK K-Purple showed the least results in both categories of catechins evaluated. The results are; EGC (0.385\%), EC (0.39\%), EGCG (4.06\%) and ECG (4.04\%). The results from the three clones evaluated, showed that gallated catechins are the most dominant than the non-gallated. The results show that $t_{c a l}=0.0289<t_{t a b}=2.353, \mathrm{P}_{c a l}=0.9783>\mathrm{P}_{t a b}=0.05$. Hence, there was no significant difference noted in all the two categories of the non-gallated and gallated catechins. The gallated and non-gallated catechins helps in reducing the

Volume 5 Issue 6, June 2016 www.ijsr.net 


\section{International Journal of Science and Research (IJSR) \\ ISSN (Online): 2319-7064}

Index Copernicus Value (2013): 6.14 | Impact Factor (2015): 6.391

glucose and cholesterol absorption in the human bodies which are the major causes of non-communicable diseases that includes; cancer, high blood pressure and arthritis.

The results for above and below ground $\mathrm{CO} 2$ sequestration showed that there was no significant difference $(\mathrm{P}<0.05)$ as far as age factor is considered. The $t_{\mathrm{cal}}=1.5378<t_{\mathrm{tab}}=3.922$, $\mathrm{P}_{\mathrm{cal}}=0.1415>\mathrm{P}_{\mathrm{tab}}=0.05$. The interval difference was $7.1927+46.4789$. This was as a result of the fact that, the $\mathrm{CO} 2$ sequestration was higher on mature clones than the less mature ones. Since, green variety clones mature fast than purple variety clones and, hence, $\mathrm{CO} 2$ sequestration was high in green variety. This also reflects to the above and below ground $\mathrm{CO} 2$ sequestration capabilities. The results showed that, the above ground sequestration rate was higher than below ground sequestration rate which was computated in $(\%)$ ratio as $64.81 \%$ and $35.18 \%$ respectively.

The difference was also noted to be due to the diameter size of the individual tea plants which was ranging from the 0.5 $\mathrm{mm}$ being the lowest at age one year and $1.8 \mathrm{~mm}$ being the highest at the age of ten years. The height was also another factor that led to the significant difference, $38 \mathrm{~cm}$ was the lowest height and $70 \mathrm{~cm}$ was the highest at one and ten years respectively.

The result showed that purple variety was leading in drought resistance $(90 \%)$ and green variety $(10 \%)$. This was due to the camouflaging of the variety whereby during the dry conditions, the purple colour tend to fed while during the wet season, the purple chlorophyll tend to increase earning it the colour purple. The resistance of frost and hailstone, green variety showed an improved resistance as compared to drought resistance. $(83 \%)$ purple and $(17 \%)$ green for frost resistance and $(71 \%)$ purple and $(29 \%)$ green. Purple variety showed a diminished response on disease and pest resistance (70\%) while green variety showed improved resistance of $(30 \%)$. The t-test result shows that there was significant difference $t_{c a l}=0.557<t_{t a b}=2.353, P_{c a l}=0.6072>\mathrm{P}_{t a b}<0.05$ for the two varieties. The highly rated resistance of purple variety was analyzed and noted to be due to the texture and colour that was achieved through advanced hybridization.

\section{Conclusion}

The results indicated that; the productivity ratios for green and purple tea varieties differ significantly due to the quality and quantity variance. The growth rate was noted that, green tea had high growthrate potential while purple tea was slightly low which was characterized by the continued hybridization to produce a complete high vigour variety that can withstand all the economic and climatic factors.

The establishment rate was determined and observed that land was the empending issue that slows down the rate of purple tea farming establishment. The population growth has led to the disintegradtion of the large tracts of land into smaller portions that hinders either complete or partial replacement with respect to the available piece of land. The extension services was perceived to be favouring the farmers with more than five (5) acres of land due to the extension of working mechanisms that can only be possible for more than five acres of land.
The $\mathrm{CO} 2$ sequestration rate for both above and below ground of purple tea variety was noticed and established that, the above ground ratio was above the below ground level. The ratios were $64.71 \%$ and $35.29 \%$ respectively for above and below ground $\mathrm{CO} 2$ sequestration. This was evidently observed as due to the structural composition of the above and below plant nature.

\section{Recommendation}

To generate data that can form basis of a comprehensive intervention on the establishment of the purple tea farming with the approach of enhancing $\mathrm{CO} 2$ sequestration capability, there is a need of developing explicit structured guidelines that depicts the aspects that are not limited to: Environmental, social and economic aspects that indicates the benefits of establishing purple tea as a mechanism of adapting to changing climatic conditions in tea sector.

There is a need for the KTDA, TBK and other relevant custodian agencies of tea marketing to provide apparent marketing structure to scale the profit between the green and purple variety, which will determine the rate of adoption of the new variety.

To establish the response level mechanism for both the green and purple variety as far $\mathrm{CO} 2$ sequestration is concerned. There is need to carry a comprehensive study with all the supportive plant growth components to be studied. The components may include: soil; water; hybridization conditions that will determine the mechanism of the adaptability and $\mathrm{CO} 2$ sequestration rates.

\section{Acknowledgement}

I acknowledge my supervisors Dr. Benson Karanja and Dr. Rebecca Karanja for their continued effort and support to ensure that I complete my study. I do also, extend a word of appreciation to my loving parents Mr. and Mrs. Kimtai for their moral and financial support to achieve my future endevours. I finally appreciate the TRFK as whole for their supportive approach to allow me in carrying out the study within their jurisdiction.

\section{References}

[1] Charles et.al (2010). Managing Agricultural Greenhouse Gases: Coordinated Agricultural Research.

[2] Creswell, J. W., \& Plano Clark, V. L. (2007).Designing and conducting mixed methods research. Thousand Oaks, CA: Sage.

[3] FAO (2006).Conservation Agriculture for Sustainable Agriculture and Rural Development. Food and Agriculture Organization of the United Nations (FAO), Rome.

[4] Füssel H.-M and Klein R. J. T (2002).Climate Change Vulnerability Assessments: An Evolution of Conceptual Thinking. Climatic Change, 75:301-329, 2006. 


\section{International Journal of Science and Research (IJSR) \\ ISSN (Online): 2319-7064}

Index Copernicus Value (2013): 6.14 | Impact Factor (2015): 6.391

[5] GoK (2010).National Climate change Response Strategy: Executive Brief. Ministry of Environment and Mineral Resources, Government of Kenya (GoK), Nairobi.

[6] IPCC (2007).Climate Change Impacts, Adaptation, and Vulnerability. Cambridge University Press, Cambridge.

[7] Kamunya, (2015).New purple tea variety promises greater returns, Magazine.

[8] Otto S, (1999).Potential Impacts of Global Warming, Geneva, Case Studies on Climate Change. Geneva, 1999.

[9] Parry et al. (2005).Climate change, global food supply and risk of hunger. Philosophical Transactions of the Royal Society of London. Series B, 360:21252138, 2005.

[10] Tea Board of Kenya, (2011). www.teaboard.or.ke.

Volume 5 Issue 6, June 2016 www.ijsr.net 